\title{
Trends of Major Research Facilities Related to Materials Science and Engineering
}

Science and technology have always been strongly influenced by materials science and engineering (MS\&E) because of materials needed to implement technology and lead science. And although MS\&E disciplines are best known as fields of individual investigator science, they have become a significant influence on the development and use of major facilities and vice versa. In this article, I explore some of the trends in MS\&E as they relate to major facilities.

In recent years, the design and understanding of new materials often require relating the microscopic properties and interactions of atoms at the atomic level to the macroscopic behavior of the material, and increasingly, this requires the use of some major facility. Also, powerful probes such as synchrotron and neutron sources have opened entirely new areas of investigation to scientists in a broad range of disciplines.

MS\&E have also altered user trends at major facilities. Unlike high energy nuclear physics facilities, where a few "big science" experiments are done year round, major facilities for MS\&E are used by numerous groups of individuals doing many experiments on many beam lines as an extension of their own laboratory studies. Another trend is the increasing use of the facilities by industry. As little as 10 years ago, most users of Oak Ridge National Laboratory's (ORNL) materials facilities were academic scientists, but now almost one-third of the users are from industry and that fraction is growing. Also, the diversity of disciplines using major facilities is increasing. Ten to 15 years ago, the major use of neutron scattering facilities was for condensed matter studies, but today, new users include chemists, biologists, astronomers, polymer scientists, medical researchers, environmental analysts, nondestructive testers, engineers, and drug and automotive manufacturers just to mention a few.

Much has been written by politicians and policymakers about the necessity of prioritizing major science projects, and although astronomy and high energy physics are often cited as fields which have done this well, it is worth noting that the MS\&E disciplines have done an exemplary job. Many reports written in the early 1970s through the 1990s justified the need for facilities in MS\&E. Perhaps the best known of these was the National Research Council report Major Facilities for Materials Research and Related Disciplines ${ }^{1}$ (so-called Seitz-Eastman report for its two well-known co-chairs Frederick Seitz and Dean E. Eastman) This pioneering report made recommendations for the development and construction of facilities in two categories: (1) major new facilities; and (2) new capabilities at existing facilities. The recommendations for construction of major new facilities were (1) a six $\mathrm{GeV}$ synchrotron radiation facility; (2) an advanced steady state neutron facility; (3) a one to two $\mathrm{GeV}$ synchrotron facility; and (4) a high intensity pulsed neutron facility.

In January 1986 in a memorandum entitled "Secretarial Site Selection Decisions on Specific Energy Research Projects," the Under Secretary of the Department of Energy (DOE) reflected these priorities of the scientific community and sited four specific Energy Research (ER) projects as part of a long-range plan to revitalize the DOE/ER laboratories. This siting memo stated that these "site decisions were made to maintain the technical viability among the Department of Energy laboratories." The facilities and selected sites were (1) Relativistic Heavy Ion Collider, Brookhaven National Laboratory; (2) One to Two GeV Synchrotron Radiation Source, Lawrence Berkeley Laboratory; (3) Six GeV Synchrotron Radiation Source, Argonne National Laboratory; and (4) Advanced Steady State Research Reactor, Oak Ridge National Laboratory. Although the order of these facilities have changed, the DOE/ER has done remarkably well in following through on this long-range revitalization plan and has now completed or started all but one of these facilities.

The remaining uncompleted facility is the research reactor recommended for Oak Ridge National Laboratory. And although design for a new research reactor, the Advanced Neutron Source (ANS), was in both the 1994 and 1995 President's Budgets as a construction line item, it was not approved by Congress either year because of total cost. In response, the DOE replaced it in the FY 1996 budget with a request for design of a lower-cost, accelerator-based spallation neutron source. At this writing, the request remains in the budget and the neutron science community may finally be on its way to acquiring a much needed new neutron source.

Has the return to science and technology been worth the investment in major facilities? Although such questions are difficult to answer, the best indication may come from considering the oldest major facilities, neutron sources, and their impact on science and, thereby, society. The 1994 Nobel Prize in Physics was shared by Clifford Shull for pioneering work he did at the ORNL Graphite Reactor in the early 1950s, and by Bertram Brockhouse for similar studies at a comparable reactor at the Chalk River Nuclear Laboratories in Canada. Their work which initiated the modern field of neutron scattering, would have been impossible without these first "major" neutron reactor facilities accessible to them at the time. Furthermore, these same facilities and their successors produced the first medical isotopes, initiated radiation damage studies and alloy development, facilitated nuclear power production, supported recent industrial developments, and much more. In the area of science alone, at least eight other Nobel Prizes have been granted between 1950 and 1994 for work done at major neutron facilities. This enviable record for science and technology is a strong testimonial of the synergism between major facilities and MS\&E, and the ultimate benefit to society.

BILl APPLETON

Bill Appleton is Associate Laboratory Director for Advanced Materials, Physical, and Neutron Sciences at Oak Ridge National Laboratory.

1. Major Facilities for Materials Research and Related Disciplines. (National Academy Press, Washington, D.C., 1984).

COSE WORKSHOP ON OPTICAL INFORMATION TECHNOLOGY Washington, DC - November 30-December 1, 1995 - Information Transport - Information Storage - Information Processing • Display

For information, contact the Committee on Optical Science and Engineering (COSE) of the National Research Council at 202-334-3520, fax: 202-334-2791, e-mail: cose@nas.edu, or the NAS homepage: URL: http://www.nas.edu. 


\section{New horizons in}

\section{materials research}

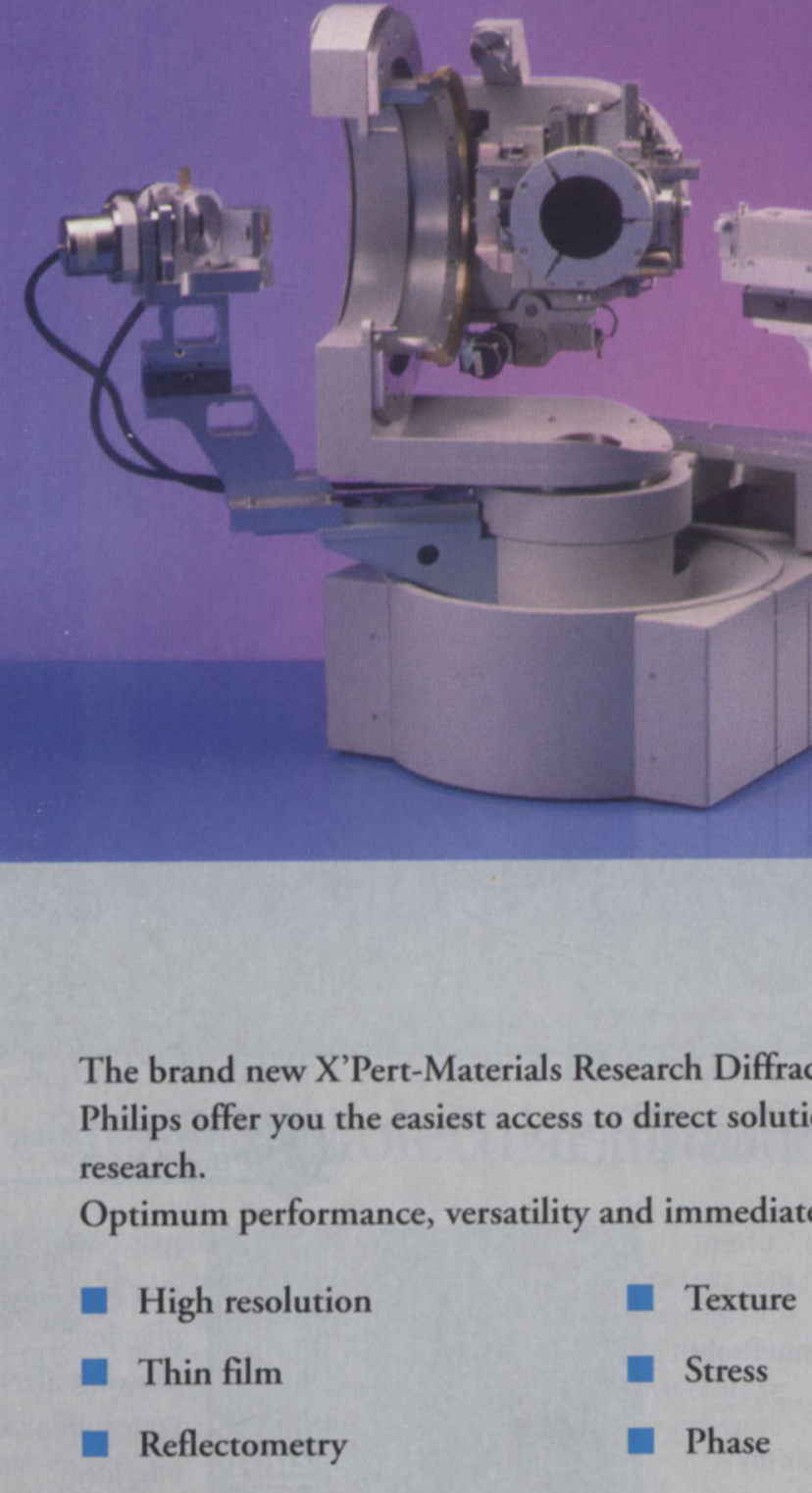

Seeing is believing

Please ask for a free demonstration disk

Visit MRS Exhibit

Booth Nos. U800-U801

Philips

Analytical

X-Ray
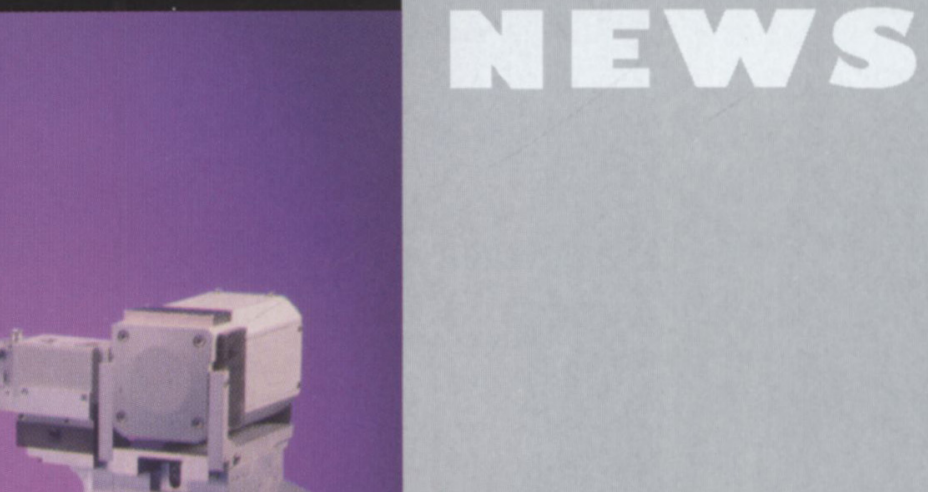

\section{(19)}

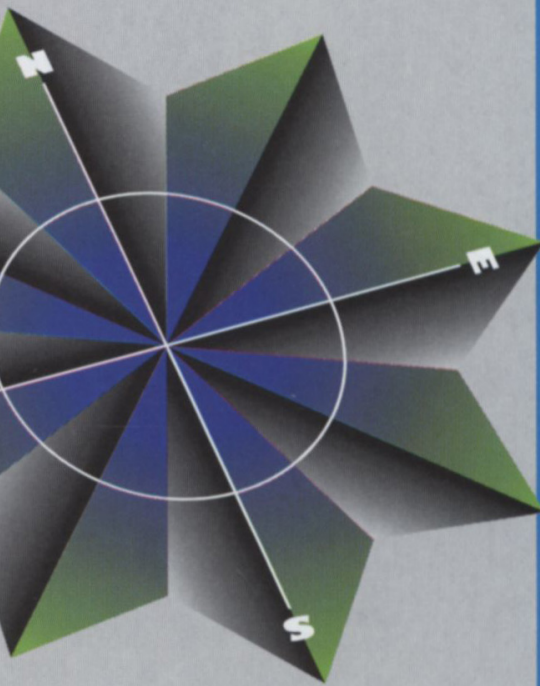

Philips Analytical X-Ray BV Lelyweg 1, 7602 EA Almelo, The Netherlands. Tel. +31 (546) 839430 . $\mathrm{Fax}+31(546) 839598$.

Philips Electronic Instruments Company 85 McKee Drive, Mahwah, NJ 07430, USA.

Tel. +1 (201) 5296246. Fax +1 (201) 5295084 . 


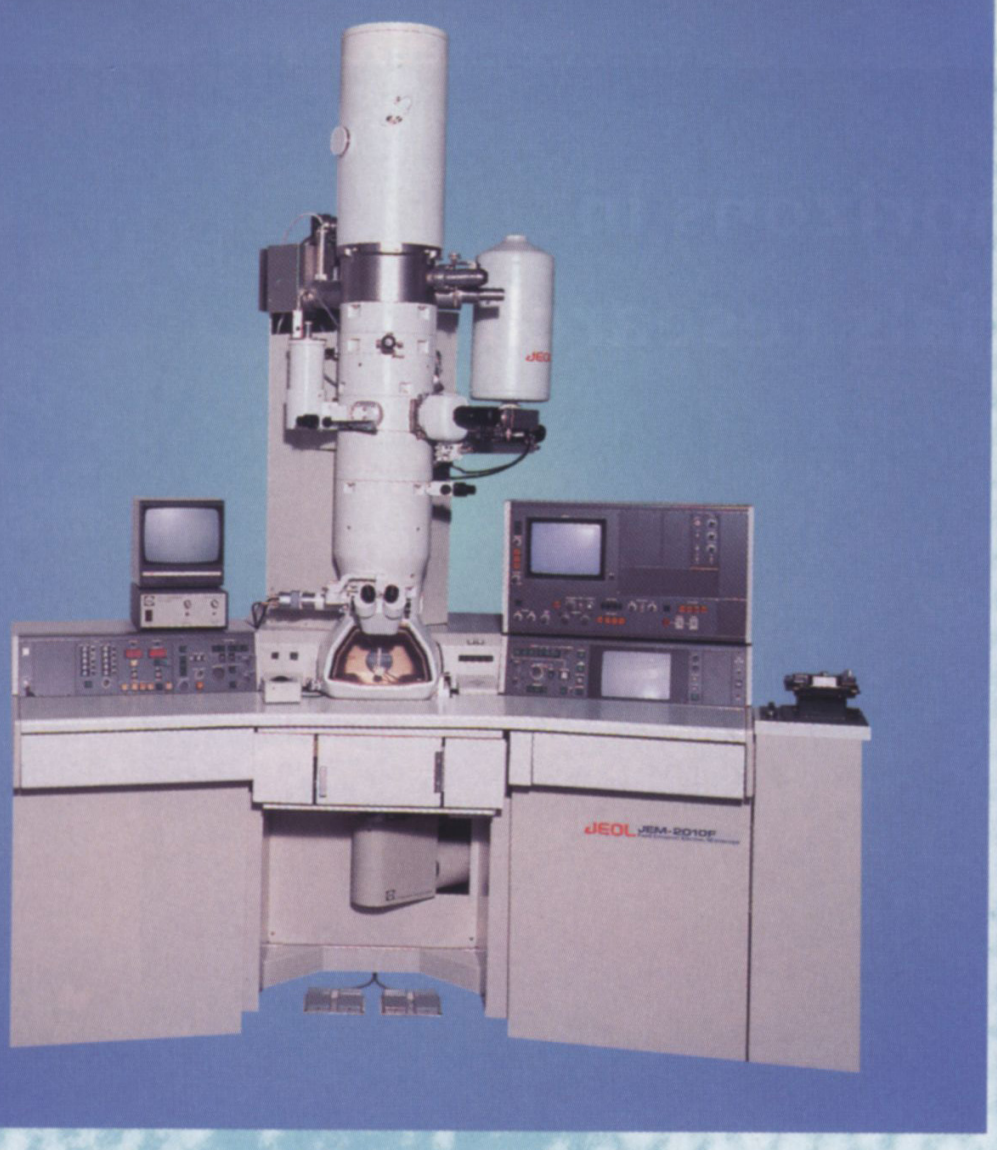

\section{Sights Unseen.}

\section{With the New JEM-2010F Field Emission Electron Microscope You'll See It ... If It's There.}

From JEOL...the newest generation of precision equipment that

permits unprecedented resolution in 3-dimensional, subnanometer analysis of microstructures.

Featuring user-friendly operation and long-term stability, the JEM-2010F also offers:

\section{Eㅡㄴㅡ}

Serving Advanced Technology
- Schottky Emission: High Current High Brightness

- High Probe Current: 0.5nm Probe with 100 pA Current

- High Resolution: Information Limit $1.4 \AA$, Scherzer $1.9 \AA$

- Holography: Option Available

- STEM Resolution: 0.2nm Magnification: 8MX

Discover the JEM-2010F and visit sights previously unseen.

JEOL USA, Inc., 11 Dearborn Road, Peabody, MA 01960
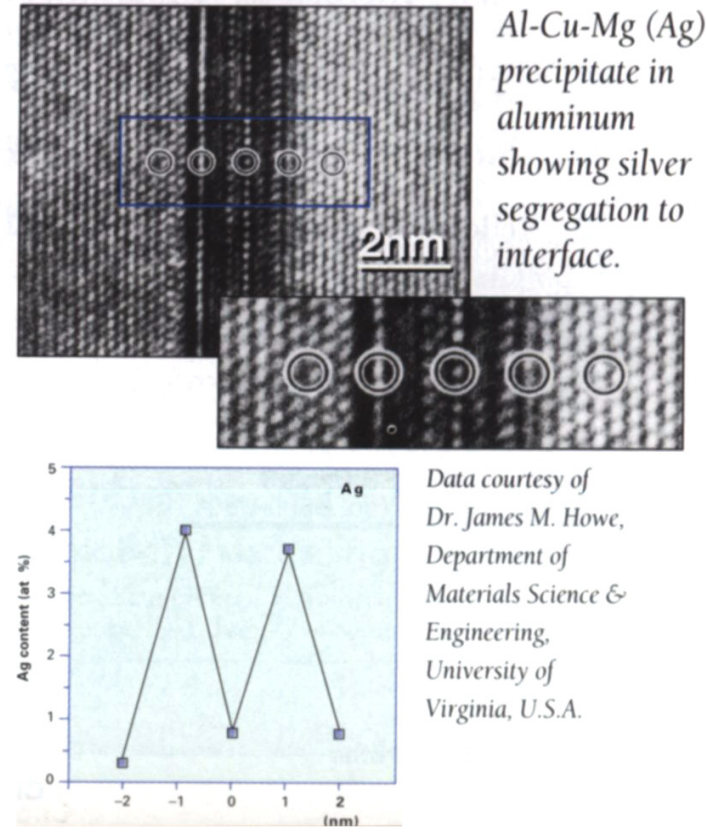


\section{There's been a change in the line-up.}

\section{BIOSYM/Molecular Simulations is leading that change.}

\section{Leading the way with Cerius $^{2}$}

Cerius $^{2}$ is changing the strategies used in chemical computing. It is first in its league in applying the best computational techniques to real world research problems. That's why there are more new users of Cerius ${ }^{2}$ in R\&D departments than ever before, Cerius em switching from previous generation products to this innovative many of them
environment.

Cerius $^{2}$ is used at over 600 different research sites around the world, in industries from oil and gas, through pharmaceuticals and chemicals, to aerospace. It's made big hits in the determination of crystal structure, design of catalysts, control of morphology, prediction of polymer properties, and interpretation of data from analytical instruments.
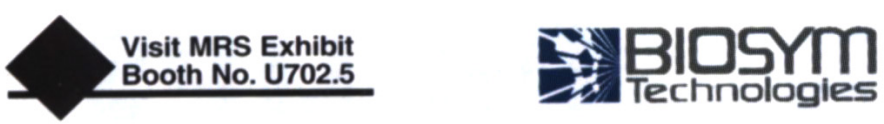

\section{Innovations of the game}

Leading the field is not enough. At BIOSYM/Molecular Simulations, we're moving further ahead. Now you can plug your own programs into the Cerius ${ }^{2}$ environment, combining the power of Cerius ${ }^{2}$ with the proprietary or thirdparty methods you use every day

Visit us at our MRS exhibit to see how BIOSYM/Molecular Simulations solutions are changing the way the game of chemical computing is being played!

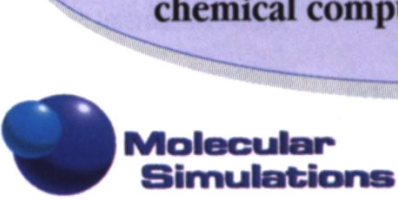

Moving Ahead Together 


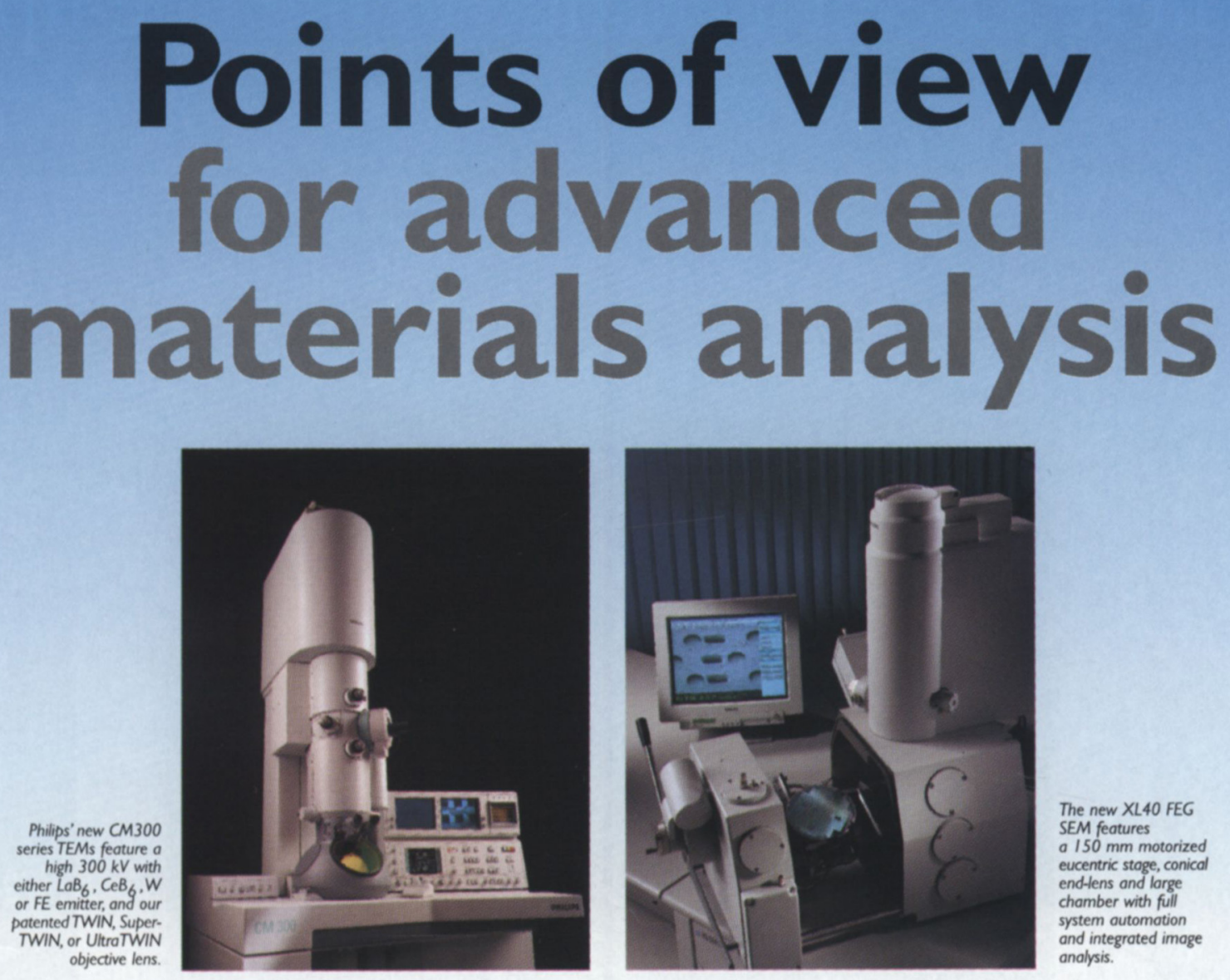

Increasingly materials research is concerned with structures at the atomic scale such as interfaces, crystal structures and defects, which determine many important materials

properties. Effective study of these phenomena require instruments that combine many types of information, all gathered at nanometre scale.

Our scanning and transmission electron microscopes blend high image quality and system performance with exceptional ease of use to provide you with the very

best points of view. And of course, you can depend on Philips for full support. If you would like to develop your own points of view about Philips electron microscopy,

fax or call for information:

Fax: 201-529 2252, Telephone: 201-529 3800

E-mail: marcom@eo.ie.philips.nl

Philips Electronic Instruments Co.

85 McKee Drive, Mahwah, NJ 07430

\section{Philips Electron Optics - More than 50 Years of Innovation}
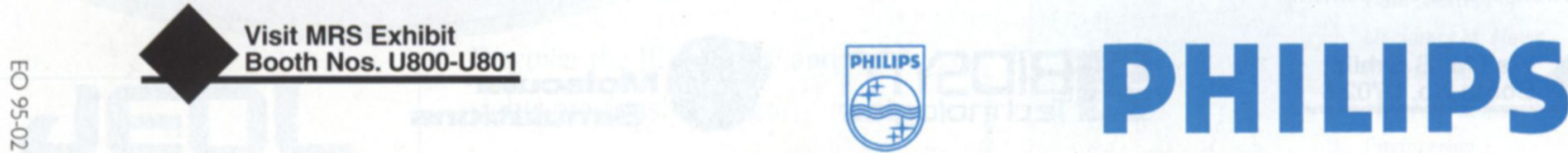

Circle No. 38 on Reader Service Card. 


\section{Materials Research Society would like to thank the following for their financial support:}

Addax SA

Advanced Control Systems Corp.

Advanced Energy Industries, Inc.

Advanced Micro Devices, Inc.

Advanced Photovoltaic Systems, Inc.

AEA Technology

Aerospace Corp.

AG Associates

Air Products and Chemicals, Inc.

AIXTRON, Inc.

Akzo

Aldrich Chemical Company

Allied-Signal, Inc./Advanced

Microelectronic Materials

Allied-Signal, Inc./Research \& Technology

Aluminum Company of America

Aluminum Research Board

American Chemical Society

American Xtal Technology

AMRAY, Inc

Anatech, Ltd

APD Cryogenics, Inc.

Applied Materials

ASTeX

Argonne National Laboratory

Asahi Glass Co., Ltd.

AST elektronik GmbH

AT\&T Bell Laboratories

ATRIX Laboratories, Inc

Automotive Composites Consortium

Balzers

Bayer Corporation

Bellcore

BIOSYM/MSI

Blake Industries, Inc.

Brookhaven Instruments Corp.

Brookhaven National Laboratory

Cabot Corp.

Cameca Instruments, Inc.

Canon, Inc.

Centre European pour le Recherche

Nucleaire (CERN)

CFM Technologies, Inc

Chemat Technology, Inc.

China Technical Consultants, Inc.

CNRS

Cober Electronics

Coherent Laser Group

Commonwealth Scientific Corp

Communications and Power Industries,

Inc.

Comstock, Inc.

Conductus, Inc.

Consortium für Elektrochemische Ind. $\mathrm{GmbH}$

Corning, Inc

Courtaulds

CREE Research, Inc

CVC Products, Inc.

Cymer Laser Technologies

Dainippon Screen Mfg. Co., Ltd.

DCA instruments, inc.

Denton Vacuum, Inc.

Digital Equipment Corp.

Digital Instruments, Inc

Dow Chemical Co.

Dow Corning Corp.

DSM Research

Dytech International

Eastman Kodak Company

Eaton Corp.

EG\&G Nuclear Instruments

E.I. duPont de Nemours \& Co., Inc.

Electric Power Research Institute (EPRI)

Electricité de France

Elsevier Science Publishing Co., Inc.

EMCORE Corp.

Energy Conversion Devices

Engelhard Corp.

Enraf-Nonius Co

EPI/MBE Products Group
ES Microware

Charles Evans \& Associates

Evans East

Extrel Corp.

Exxon Production Research Co.

Exxon Research and Engineering $\mathrm{Co}$.

Federal Highway Administration

FEI Co.

E.A. Fischione Instruments, Inc.

Fisons Instruments

Ford Motor $\mathrm{Co}$.

Fuji Electric Co., Ltd.

Fujikin of America, Inc.

Gas Research Institute

Gatan, Inc.

Gelest, Inc.

Genentech, Inc.

General Electric Co.

General Motors Research

Genus, Inc.

Golden Technologies

Goodfellow Corp.

Gordon \& Breach Publishers, Inc

Granville-Phillips Co.

Groupe de Dynamique des Phase

Condenses

Haldor Topsøe A/S

Hauzo Techno Coating Europe

Hewlett-Packard $\mathrm{Co}_{0}$

High Voltage Engineering Europa B.V.

Hitachi, Ltd.

Hitachi Scientific Instruments

Hoechst AG

Hoechst Celanese Research Division

Howmedica

Hughes Research Laboratories

Huntington Mechanical Laboratories

IBM AdStaR

IBM Analytical Services

IBM Corp.

IHI Research

Inorgtech

Institut für Schicht und Ionentechnik (ISI)

Institute for Scientific Information (ISI)

Institute of Physics Publishing (IOP)

Instron Corp.

Instruments SA, Inc./Riber Division

Intel Corp.

International Center for Materials Research (ICMR)

Ion Tech, Inc.

ITAC, Ltd.

JCPDS-International Centre for Diffraction

Data

JEOL USA, Inc.

Johnsen Ultravac

Johnson Controls, Inc

Johnson \& Johnson

Johnson \& Johnson Professional

Kaneka Corp.

Kawasaki Steel Corp.

Keithley Instruments, Inc.

Kimball Physics, Inc.

Kobe Steel USA, Inc.

Komag, Inc.

Kratos Analytical, Inc.

Kyocera Corp.

Lafarge Fondu International

Lake Shore Cryotronics, Inc.

Lambda Physik, Inc.

Lawrence Berkeley Laboratory

Lawrence Livermore National Laboratory

Lawrence Semiconductor Research

Laboratory

Legacy Systems, Inc

Kurt J. Lesker Co.

Lockheed Idaho Technologies Co.

Lockheed Martin Energy Systems

Los Alamos National Laboratory

Lumonics, Inc.

Magnet Sales \& Manufacturing $\mathrm{Co}$.
Marcel Dekker, Inc.

Martin Marietta Energy Systems, Inc

Materials Research Corp.

Materials Research Group

MCP Wafer Technology, Ltd.

MDC Vacuum Products Corp.

Medisorb Technology International

MEL Chemicals

MEMC Electronic Materials

MER Corp.

Microwave Materials Technologies, Inc

Millipore Corp.

Mitsubishi Electric Semiconductor

Laboratories

Mitsubishi Materials Corp

Mitsui Engineering \& Shipbuilding Co., Ltd.

Mitsui Toatsu Chemicals, Inc

MKS Instruments, Inc.

Morton Advanced Materials

Motorola APRDL

MR Semicon, Inc.

MVSystems, Inc.

n\&k Technology

Nano Instruments, Inc.

Nanophase Technologies

Nanotec Corp.

NASA Lewis Research Cente

National Electrostatics Corp.

National Renewable Energy Laboratory (NREL)

National Semiconductor

NEC Corp

NEC Research Institute, Inc.

Neocera, Inc.

New Focus, Inc

Niki Glass Co.

Nikko Hitech International, Inc.

Nippon Oil Corp.

Nippon Steel Corp.

Nissei Sangyo America, Ltd.

Nor-Cal Products, Inc.

Northern Telecom, Ltd

Novapure Corp.

Nuclear Regulatory Commission

Oak Ridge National Laboratory

Omicron Associates

OnTrak Systems, Inc.

OPTOVAC

Oxford Applied Research

Park Scientific Instruments

Paterson Instruments PTY, Ltd

Perseptive Biosystems, Inc.

Philips Electronic Instruments Co. (PEI)

Physical Electronics

Plasma Sciences, Inc.

Plasma-Therm, Inc.

Plenum Publishing $\mathrm{Co}$.

Portland Cement Association

Precision Manufacturing Cente

President Enterprises Co.

Princeton Gamma-Tech, Inc.

Pure Tech, Inc.

Quantum Design, Inc.

Read-Rite Corp.

Research and PVD Materials Corp.

Rexham Custom

RHK Technology

Rigaku/USA, Inc

RIMCOF

Rockwell International Corp.

ROITECH

Sandia National Laboratories

Santa Clara Plastics

Sanyo Electric Co., Ltd.

Schlumberger Doll Research

Schumacher/Air Products \& Chemicals Unit

Seagate Technology, Inc.

Sematech, Inc.

Semiconductor Processing $\mathrm{Co}$.

SGS-Thomson Microelectronics

Sharp Corp.

Siemens Analytical X-Ray Instruments, Inc.

Siltec Silicon

Smith \& Nephew Research, Ltd.

Solarex Corp.

Solartron Instruments

Solid State Equipment Co.

Sony Co., Ltd.

SOPRA, Inc.

South Bay Technology, Inc.

Southwest Research Institute

Spectra-Physics Lasers, Inc.

Spire Corp.

Springer-Verlag New York, Inc

Staib Instrumente $\mathrm{GmbH}$

Strem Chemicals, Inc

SubMicron Systems, Inc.

Sumitomo Electric USA, Inc.

Sumitomo Sitix Corporation

Superior Vacuum Technology, Inc.

Surface/Interface, Inc.

TDA Research

Telemark

Tencor Instruments

Texas Instruments, Inc.

Thermionics Laboratory, Inc.

3M Fiber Optics

Tokyo Instruments, Inc

Topcon Technologies, Inc.

TopoMetrix Corp.

Toray Industry, Inc.

Toshiba Corporation

Toyota Central R\&D Laboratories, Inc.

Ultram International

United Solar Systems Corp

Universal Instruments Corp.

USG Corporation Research Center

Vacuum Barrier Corp.

Vacuum Metallurgical $\mathrm{Co}$

Vacuum Science Instruments GmbH (VSI)

Varian Associates, Inc.

Varian Associates, Inc./Continenta

Electronic Division

VCH Publishers, Inc 


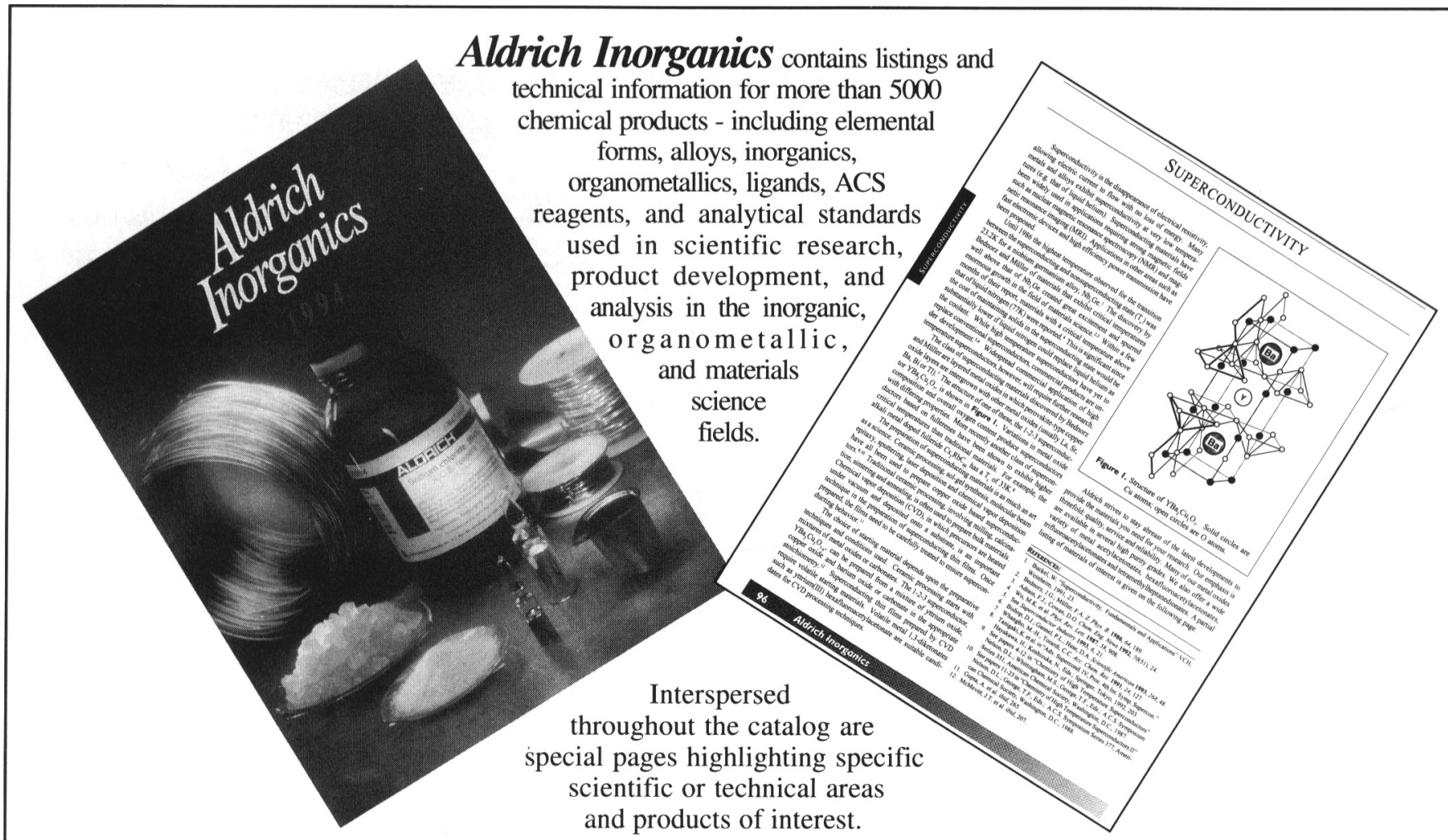

\section{If you are looking for:}

\section{Product Selection}

More than 5000 products ready for shipment,

including many advanced materials made in our own production laboratories

\section{Technical Support}

Includes years of experience in many specialized fields, combined with a database of technical and analytical information at your disposal

\section{Quality Assurance}

Based on technical

expertise and state-of-the-

art instrumentation

dedicated to this segment

of our business

\section{The Newest Tool for Chemists from Aldrich}

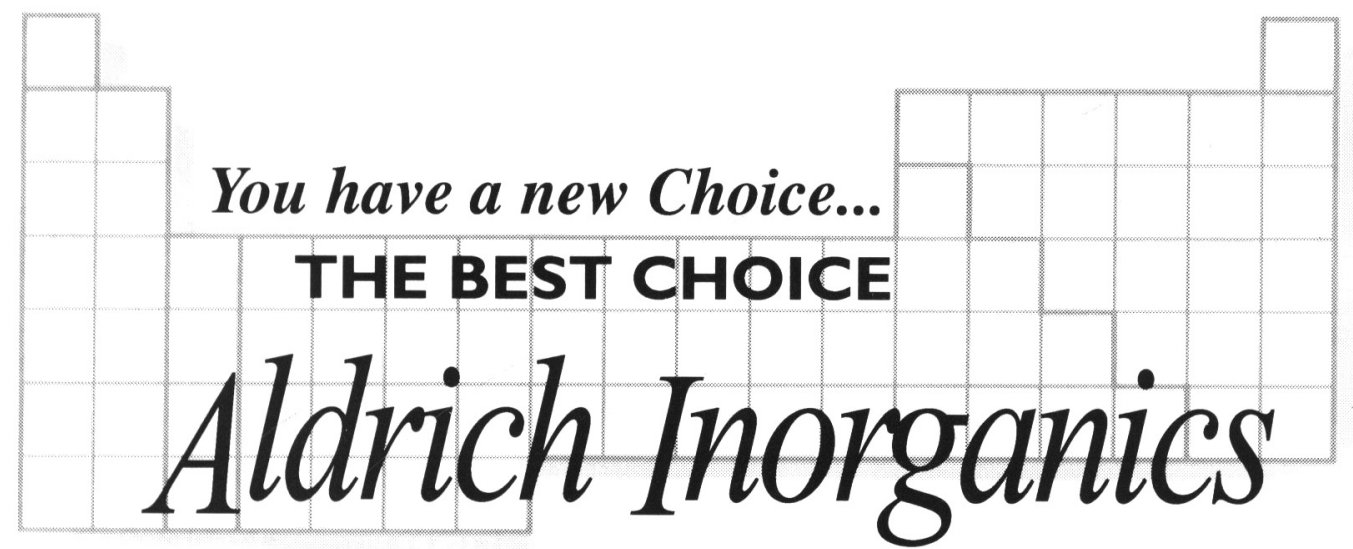

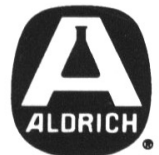

Visit MRS Exhibit Booth No. U407

\section{Call Today for a FREE Copy!}

$\left.\left.\begin{array}{|l}\begin{array}{l}\text { USA \& Canada } \\ (800) 227-4563\end{array}\end{array}\right] \quad \begin{array}{c}\text { International } \\ \text { (414) } 273-3850\end{array}\right]\left[\begin{array}{c}\text { or Fax } \\ \text { (414) } 273-2094\end{array}\right.$

Circle No. 5 on Reader Service Card. 